\section{Disciplinary Bias, Money Matters, and Persistence: Deans' Perspectives on Science Faculty with Education Specialties (SFES)}

\author{
Seth D. Bush, ${ }^{+\pi *}$ Michael T. Stevens, ${ }^{+\pi}$ Kimberly D. Tanner, ${ }^{8 \pi}$ and Kathy S. Williams $\|^{\text {\% }}$ \\ ${ }^{\dagger}$ California State Polytechnic University, San Luis Obispo, San Luis Obispo, CA 93407; "Utah Valley \\ University, Orem, UT 84058; \$San Francisco State University, San Francisco, CA 94132; 'San Diego \\ State University, San Diego, CA 92182
}

\begin{abstract}
The phenomenon of embedding Science Faculty with Education Specialties (SFES) in science departments is well documented. However, the perspectives of academic leaders have not been systematically studied. To investigate these perspectives, we conducted an interview study of college of science deans in the California State University system, which offers a defined higher education context in which to sample across a range of institution types and cultures. While deans were aware of and positive about SFES as potential change agents, most deans also evidenced casual bias against science education efforts and experts. Deans mentioned that education reform efforts by SFES were primarily driven by external policy and funding mandates, causing concern that support for such positions and scholarly work could evaporate if external pressures recede. The majority of deans stated that the SFES phenomenon had persisted over the last decade and continued to grow. Findings reported here document tacit assumptions that science education efforts may not count as science and reveal a lack of cultural integration of science education efforts into the sciences in higher education. Such findings should give biology educators, reformers, and researchers pause, as well as fresh incentive to engage more fully and regularly with administrators about their work.
\end{abstract}

\section{INTRODUCTION}

Calls to improve science, technology, engineering, and mathematics (STEM) education have spanned multiple decades (Brainard, 2007; Holm et al., 2011) and continents (e.g., Organisation for Economic Co-operation and Development [OECD], 2007; Hénard, 2009; President's Council of Advisors on Science and Technology [PCAST], 2012). Over time, various approaches to science education reform-in K-12 science education, undergraduate science education, and/or science education researchhave included the development of innovative curriculum, engagement of instructors in pedagogical professional development, increased commitment to science education research, and re-envisioning of the goals of STEM education, to name a just few (e.g., National Science Board, 2007; American Association for the Advancement of Science [AAAS], 2011; National Research Council [NRC], 2012; PCAST, 2012; Next Generation Science Standards Lead States [NGSS], 2013). Increasingly, it has become clear that many of these reform approaches have been supported by the appointment of specific individuals with a focus on STEM education within STEM departments in higher education. These individuals occupy a range of position types, which differ in tenure-status, teaching load, research responsibilities, enfranchisement, and relation to other faculty (Bush et al., 2006, 2008; Coleman et al., 2019). The majority of SFES are tenured or tenure track (Bush et al., 2013, 2016). In some institutions, however, these individuals are non-tenure track instructors who primarily teach, whereas in
C. Gary Reiness, Monitoring Editor Submitted Nov 25, 2019; Revised Jun 10, 2020; Accepted Jun 17, 2020

CBE Life Sci Educ September 1, 2020 19:ar34 DOI:10.1187/cbe.19-10-0202

"All authors contributed equally to the research and writing of this article and are listed alphabetically.

*Address correspondence to: Seth D. Bush (sbush@acalpoly.edu).

(c) 2020 S. D. Bush, M. T. Stevens, K. D. Tanner, and K. S. Williams. CBE-Life Sciences Education (c) 2020 The American Society for Cell Biology. This article is distributed by The American Society for Cell Biology under license from the author(s). It is available to the public under an AttributionNoncommercial-Share Alike 3.0 Unported Creative Commons License (http:// creativecommons.org/licenses/by-nc-sa/3.0) "ASCB®" and "The American Society for Cell Biology ${ }^{\circledR}$ " are registered trademarks of The American Society for Cell Biology. 
other institutions novel tenure-track teaching-professor positions have been created (Association of American Universities, 2017; University of California Office of the President, 2018; Harlow et al., 2020). In other institutions, these individuals are hired as discipline-based education researchers (DBER), but then are expected to participate in education reform beyond their scholarship (NRC, 2012; Bush et al., 2019). In still other instances, these education specialists are scientific trainees, often postdoctoral fellows, who partner with permanent faculty to foster innovation and change (Wieman, 2009, 2017; Bush et al., 2010; Chasteen and Code, 2018). Regardless of the specifics of these different position types, how well education positions will be accepted and integrated into the culture of the natural sciences is unclear (Brownell and Tanner, 2012; Wooten, 2018, 2019), and little systematic research has been conducted on most of these models.

One exception has been the systematic research conducted on the phenomenon of science faculty with education specialties (SFES) over the last decade and a half (Bush et al., 2006). In an attempt to be inclusive, SFES have been conceptualized as individuals contributing to STEM education reform from a wide variety of academic position types in STEM departments in colleges and universities (Bush et al., 2006). While such individuals exist across STEM disciplines, research describing the nature of the SFES phenomenon has focused on these positions in science departments, in particular in biology, chemistry, geoscience, and physics departments. As described previously, SFES are trained primarily as scientists and have additional expertise in $\mathrm{K}-12$ science education, undergraduate science education, and/or science education research (Bush et al., 2008, 2011). This integration of science education as an area of professional work in the natural sciences is being accomplished by SFES who are hired by science faculty colleagues and administrators who appear to see the need for educational reform and change agents in their departments (Bush et al., 2017, 2019). SFES are found across institution types (Bush et al., 2013) and appear to influence the teaching practices of their science department colleagues, in addition to conducting science education research and contributing to $\mathrm{K}-12$ science education in some cases (Bush et al., 2016, 2017). SFES assert the critical role of administrators in motivating SFES hires, which is consistent with administrators conceptualizing SFES as change agents who can foster educational change from within science departments (Addy et al., 2015; Bush et al., 2016). Even though the SFES phenomenon has been studied intensively for over a decade (Bush et al., 2019), perspectives of administrators about the SFES phenomenon have received only limited discussion (Bush et al., 2017, 2019).

The intent of academic leaders, such as deans, in hiring SFES to pursue science education endeavors in their colleges is unclear. In particular, the investment in academic positions focused on science education, in some cases with accompanying status and intellectual freedom, is nontrivial. Yet the motivations for creating these positions has neither been publicly articulated nor directly derived from either policy or mandate. Understanding academic leadership at the level of deans-individuals who oversee and lead multiple disciplinary departments in the sciences and beyond-is key to understanding motivations driving the SFES phenomenon, in particular the likelihood that SFES will persist in the long term and become integrated into the culture of academic science. Scholarly work on the influence of academic deans has described how deans are pivotal in determining how a college will respond to change, regardless of leadership style (Jones and Rudd, 2008). In one study, respondents nominated deans more often than presidents as important academic leaders on campus (Martin, 1993). Additionally, deans occupy unique administrative roles as liaisons between disciplinary departments and university administrators on policy, budgetary, and personnel issues. Deans' efforts can be accomplished as they cultivate relationships with individuals and groups across campus (Martin, 1993) and both develop and sustain science education reform programs (May et al., 2013). Finally, some evidence suggests that deans are key in the establishment of inclusive departmental cultures (Bystydzienski et al., 2017). However, the extent to which deans' support for the SFES phenomenon reflects either a transient response to calls for education reform or a long-term commitment to bringing science education into the culture of science disciplines has yet to be probed.

To investigate the perspectives of academic leaders about the SFES phenomenon, we conducted an interview study with deans who lead colleges of science. We chose to interview deanlevel administrators, as these individuals oversee multiple science departments, make decisions about hiring and firing, have an inherently cross-disciplinary lens, and set the culture and priorities across an entire college, unlike chairs, who are often faculty peers serving short terms and focused on a single discipline. Additionally, deans are often the highest level of campus administrators with whom most faculty, including SFES, regularly interact. We also chose to conduct these interviews in the context of the 23-university California State University (CSU) system, which includes PhD-granting, MS-granting, and primarily undergraduate institutions (PUI; CSU 2019c). Because these 23 campuses include institutions that differ substantially in their founding dates, settings, student populations, enrollment sizes, and levels of research orientation, their collective variety reflects many other colleges and universities across the nation. The CSU has the additional advantage of systematic evidence collection about the SFES phenomenon over the last decade (Bush et al., 2008, 2019). While much could be probed in these interviews, we focused our evidence collection efforts on five main research questions: 1) To what extent are deans aware of the SFES phenomenon? 2) How do deans conceptualize SFES? 3) What are deans' perceptions of SFES impacts? 4) What are deans' perceptions about the motivations for inclusion of SFES in science departments? 5) How do deans perceive the evolution of the SFES phenomenon over the last decade?

\section{METHODS \\ Participant Population}

To investigate deans' perspectives on the SFES phenomenon, our goal was to interview current or former CSU deans whose colleges included science departments and who had held their positions for at least two academic years. In Spring 2017, we identified the current science dean of each CSU campus. If the current dean had served for fewer than two academic years, we identified the closest predecessor who had served as dean for at least two academic years and invited that individual's participation instead. All of the deans interviewed in this study were from STEM-based academic disciplines themselves. 
Our target dean participants had many demands on their time, and issues involving SFES likely represented only a small portion of their professional responsibilities. As a result, we were mindful of the time commitment requested for dean interview participation. To maximize the number of deans willing to participate in this study, while ensuring that our interview protocol would generate a rich data set, we elected to request only a 30-minute interview.

Initial contacts with deans were made by email in June 2017, where we described the nature of our study. We asked them to provide informed consent, their telephone contact information, and times they were available for an interview. Participants were scheduled for telephone interviews using the contact information they provided. Before the interview, we provided each participant with our research goals, the categories of questions that we would ask, the identities of the researchers who would conduct the interview, and assurances of confidentiality. Two deans selected using this protocol had served a relatively short time and strongly encouraged us to interview a previous or current dean who they felt had critical experience with and knowledge of the SFES situation and its history on that campus. In those two cases, we interviewed a second dean from that campus. Between July 2017 and January 2018, 24 deans from 22 of the 23 CSU campuses completed a phone interview with us $(96 \%$ campus response rate).

\section{Data Collection}

Interviews were conducted by two interviewers, one of whom asked the majority of questions, and captured an audio recording. The second interviewer was present to ensure consistency in the interview protocol and to capture a backup recording. All participants agreed to be recorded and to have their interviews transcribed. Although participants were addressed by their actual names during the interviews, randomly generated numbers replaced actual names for transcription and analyses. In writing results, we redacted institution names to protect the identities of our participants. We offered to provide a copy of the interview transcript to participants upon request. Additionally, all participants were invited to review this article before its submission for publication.

These semistructured interviews were conducted using a protocol that included an informational preamble followed by questions related to our five specific research questions: 1) To what extent are deans aware of the SFES phenomenon? 2) How do deans conceptualize SFES? 3) What are deans' perceptions of SFES impacts? 4) What are deans' perceptions about the motivations for inclusion of SFES in science departments? 5) How do deans perceive the evolution of the SFES phenomenon over the last decade? For a complete interview protocol, please see the Supplemental Material. The interview questions posed were designed specifically to probe responses to the five research questions, and depending on the participant's response, follow-up questions were asked to probe their perceptions of the SFES phenomenon. Although we used a consistent interview protocol, not all participants spoke to all issues. The data we present here provide insights into a subset of claims that emerged from the responses to the study questions.

\section{Data Analyses}

Our data analyses were both qualitative and quantitative. Qualitative analyses centered on the identification of quotes from the deans' transcripts that contained evidence relevant to any of our five research questions. Quantitative analyses were post hoc and focused on closed-ended questions that emerged after the interviews were completed and that related to deans' awareness of, conceptualization of, and perceived impacts of SFES, as well as the evolution of the SFES phenomenon within their colleges.

\section{Qualitative Analysis}

To familiarize ourselves with the data set as a whole, each researcher read the 24 transcripts in their entirety. We then randomly divided transcripts equally among researchers, and each researcher examined the assigned transcripts, identifying quotes that contained evidence about any of the five research questions. As a research team, we discussed the selected quotes and identified claims about the SFES phenomenon supported by evidence from multiple deans. Claims were clarified and discussed until the four researchers reached consensus. Next, we apportioned claims equally, and each researcher identified the most illustrative quotes across all deans that provided evidence for each of the claims. Those quotes provided the evidence that supported the claims emerging from the transcripts.

\section{Post Hoc Quantification}

All four researchers read each of the transcripts entirely and looked for answers to closed-ended questions-about the deans' awareness of, conceptualization of, and perceived impacts of SFES, as well as the evolution of the SFES phenomenon within their colleges-that emerged after the interviews were completed. All four researchers reached consensus on the results.

Awareness: Had the dean heard the term "SFES" before this interview? Did the dean know of the SFES phenomenon? Did the dean's college presently have faculty who were hired as SFES (H-SFES), who transitioned to an SFES role after being hired for another role (T-SFES), or both?

Conceptualization: Had the dean perceived a status differential between SFES and non-SFES on their campus? Did the dean hold a generally positive or negative attitude toward discipline-based education research (DBER)? Did the dean hold a generally positive or negative attitude toward the SFES phenomenon?

Perceived impacts: Was the dean aware of SFES scholarly activity in K-12 science education, undergraduate science education, and/or science education research?

Evolution of SFES: Were there more or fewer SFES on their campus than in 2008, when the first study of SFES in the CSU was done? Had SFES recently been hired into the dean's college?

\section{Institutional Review}

This study was approved by the Institutional Review Board (IRB) at California Polytechnic State University, San Luis Obispo, as well as by the campuses of all coauthors. Participants provided informed consent before participation following a procedure approved by the aforementioned IRB. 


\section{RESULTS}

We present here findings from interviews with 24 deans from the CSU system, investigating their views on the SFES phenomenon. These deans represented 22 of the 23 CSU campuses at which faculty who identify as SFES and have participated in previous studies are employed (Bush et al., 2019). All deans had been in their current positions for at least two academic years, with one-third of the deans having been in their positions for longer than a decade and another third in their positions for 5-10 years. Results are organized into sections addressing the following five research questions: 1) To what extent are deans aware of the SFES phenomenon? 2) How do deans conceptualize SFES? 3) What are deans' perceptions of SFES impacts? 4) What are deans' perceptions about the motivations for inclusion of SFES in science departments? 5) How do deans perceive the evolution of the SFES phenomenon over the last decade?

Evidence presented in the following sections includes qualitative evidence-anonymized quotes transcribed directly from interviews, as well as quantitative evidence that estimates post hoc the prevalence of an emergent theme across all individuals where possible. Given the limited interview time available with deans, post hoc quantification was not always possible, as some emergent themes did not arise in some interviews and were not probed in every interview, given the initial interview protocol. In the quotes included here, we share multiple examples of deans' perceptions of the SFES phenomenon, representing voices from 17 of the 24 deans in our study. Additional quotes (including the voices from four more deans) are included in Supplemental Table 1.

\section{Research Question 1: To What Extent Are Deans Aware of the SFES Phenomenon?}

Deans across the CSU system were generally aware of the SFES phenomenon, if not the specific term "Science Faculty with Education Specialties" or "SFES." Ninety-two percent (22 of 24) of deans knew of the SFES phenomenon, whereas only $42 \%$ (10 of 24 ) had heard the specific term (Figure 1A).

\section{A. Familiar with SFES phenom.}

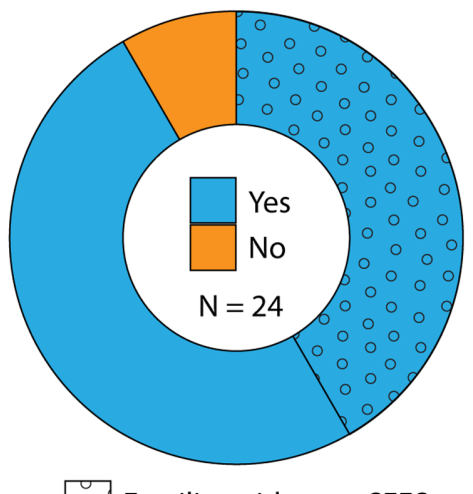

Familiar with term SFES

\section{B. Types of SFES in deans' colleges}

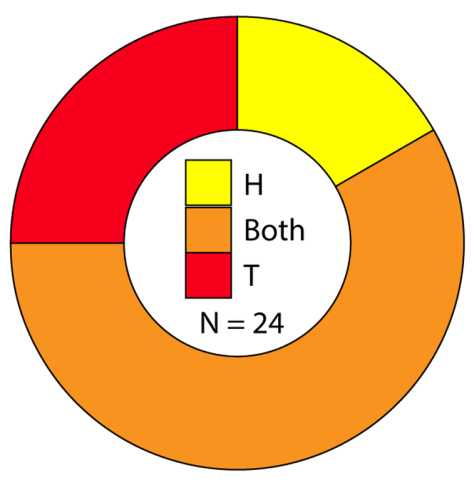

\section{Impression of SFES phenom.}

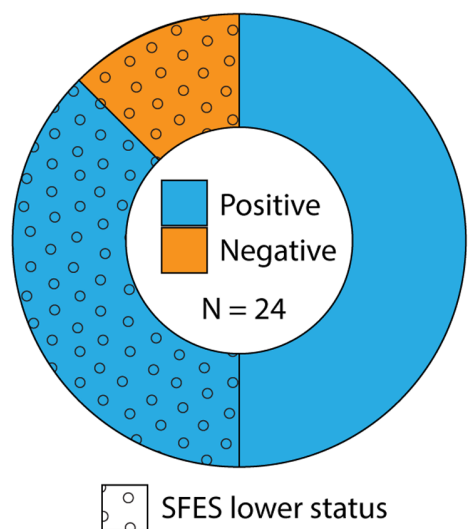

D. Negative impression of the DBER field

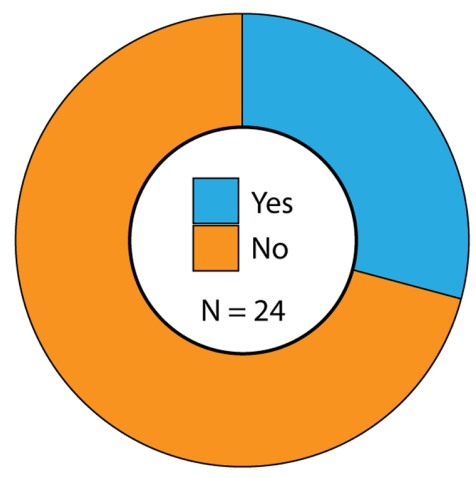

FIGURE 1. Deans' awareness, impression, and conceptualization of SFES in their colleges. (A) Deans' familiarity with the SFES phenomenon (22 of 24 yes, two of 24 no) overlapped by their familiarity with the term SFES (10 of 24; dots). (B) Deans' reflections on the presence of faculty specifically hired $(H)$ in SFES roles or those who transitioned (T) into SFES roles (four of 24 only H-SFES, six of 24 only T-SFES, and 14 of 24 both H-SFES and T-SFES). (C) Deans' impressions of SFES (21 of 24 positive, three of 24 negative) overlapped by their perception that SFES may be considered of lower status by college peers (12 of 24; dots). (D) Deans with a negative impression of DBER (seven of 24 yes, 17 of 24 no).

"We didn't use that term but, yeah we definitely have those ... we called them discipline-specific science educators, but it's the same thing."-Dean 147

"So this is [not my first] institution, and I am used to there being educators in the discipline or department. So, mathematics educators in mathematics departments, science educators in science departments, and also in the College of Education ... the people who work on science education are a combination of people who were educated that way or people who were educated as scientists but then transitioned into science education."-Dean 140

All participating deans reported having had SFES on their campus. As alluded to in the last quote, deans reported having different types of SFES in their colleges (Figure 1B), with $58 \%$ (14 of 24) of deans reporting that they had both H-SFES who had been specifically hired into that role and T-SFES who had transitioned from basic science activities into an education specialty role. Additionally, 25\% (six of 24) of deans reported having only T-SFES, and 17\% (four of 24) reported having only H-SFES.

The vast majority of deans $(88 \% ; 21$ of 24) across the CSU system expressed positive impressions about the SFES phenomenon and its impact on their campuses, fewer than $13 \%$ (3 of 24 ) reported a negative impression of SFES (Figure 1C). In some cases, the deans' positive impressions of the SFES phenomenon were expressed as aspirations to bring more SFES to their campus in the future, as seen in the following quotes. 
"I'm very happy that I hired the couple faculty that fit that [SFES] description ... And our Science Faculty with Education Specialties have been incredibly successful. ... My long-range goal was to have one in each department in the college."Dean 106

"I think every one of the departments could benefit by having someone like that in there, because the introductory core courses, in all of them, are always needing updates, changes, looking at what is best for how you teach students."-Dean 138

\section{Research Question 2: How Do Deans Conceptualize SFES?} Across all dean interviews, SFES were primarily conceptualized as scientists who happened to be working on issues of science education within a science department. While some described SFES as individuals who had additional training in science education, deans generally conceptualized SFES as "card-carrying scientists," a term that was used by multiple deans. However, even with formal training in their science disciplines, many deans also expressed concern that SFES would be considered "second-class citizens," given the nature of their professional work and its focus on education. Language from dean interviews further evidenced the underlying status differentials between education and science that pervades their conceptions of the SFES phenomenon.

\section{SFES as Card-Carrying Scientists}

Deans repeatedly described SFES as scientists with PhD-level training in their science disciplines and commonly linked their scientific credentials and research training with the level of respect, credibility, and influence that SFES were likely to garner from fellow science faculty:

"... I think one of the things that we were lucky with, that made it work, is the particular people we hired, as it happened, actually had $\mathrm{PhDs}$ in the subjects, as opposed to $\mathrm{PhDs}$ in education .... And that gave them a lot of credibility with the fellow faculty."-Dean 106

“... And there's a very strong sense in science faculty, probably a lot of other faculty too, to pay most attention to people that you think have calling cards in their discipline, credentials in their discipline ... So the disciplinary expertise, I view, as making a big difference."-Dean 135

Concomitantly, several deans recalled unfortunate stories of SFES who did not come to their role with discipline-specific training and credentials in the basic sciences, but rather with formal education training and expertise in $\mathrm{K}-12$ education or science education more generally:

"... my experience is that when you hire faculty that have a background in $\mathrm{K}-12$ education and you put them in the science departments, your basic science researchers, your hard science researchers, look down upon them. And it tends to be a very negative experience for those faculty. And so they often end up being moved over to the College of Education because they feel like they're never going to get tenure and [be] promoted because they're doing education research, but they're not doing the hard science basic research. So, they're treated as second-class citizens, or maybe even—not even citizens? And that's very difficult. It's across the board. It's a perception that they're not as smart. They're not as good. They don't have as much knowledge."-Dean 117

"Unfortunately, our one person who is a specialist has had issues, and I saw those same issues on my other campus with people who were hired as science education specialists and had a hard time getting the respect of their colleagues. Their colleagues had a hard time understanding their research and appreciating their research. So, it partly was a matter of disciplinary hegemony."-Dean 139

\section{Concerns about Perceived Lower Status}

Deans raised concerns regarding the perceived status of SFES and also about their DBER efforts. Half of the deans surveyed expressed concern that SFES may be considered of lower status by their college peers (Figure 1C), notably this concern was held by a sizable portion of deans (nine of 21) who expressed a positive impression of the SFES phenomenon. Further, just under a third of deans (seven of 24) indicated a negative impression of DBER (Figure 1D). Even for those SFES who were "card-carrying scientists" and at the PhD-level within their disciplines, some deans shared concerns about perceived lower status of these individuals, based on the nature of their professional work, scholarly activities, and publications:

"In my role as dean, [I see] that some of their colleagues wouldn't view publications about those efforts, those pedagogical efforts, as being as important toward tenure. But I made it clear that in my view as dean, I think that having them engaged in doing scholarship around the scholarship of teaching and learning was an important contribution to the college and to the students."-Dean 126

"Faculty in these arenas, my understanding is, can also be involved in K-12 developments, programmatic developments, and interfacing between $\mathrm{K}-12$ and [the] university. But faculty as a whole have lesser understanding of that and don't view it perhaps as high a level of scholarship. They view it much more as service."-Dean 129

"... at our campus, education, science education research, is respected. But I'm not sure that is a universal thing. So, when in fact, [a chancellor's office visitor] was here, I didn't get the impression that he was as impressed with education research as he was with research-research."-Dean 132

Multiple deans acknowledged that cultural acceptance of SFES and discipline-based science education as legitimate scholarly activity within the science disciplines varied not only across campuses but also across disciplinary departments on a single campus, often taking pride in their communities' inclusion of SFES and science education in their science disciplines:

"So in earth sciences and physics, we were way more welcoming to the science education researchers ... And particularly, chemistry, they were very challenged by that ... there was this first- and second-class citizen kind of thing going on ... And in biology, their science education folks were not as explicitly science education as in the other departments."-Dean 147 


\section{A. Deans' perceptions of SFES impact}

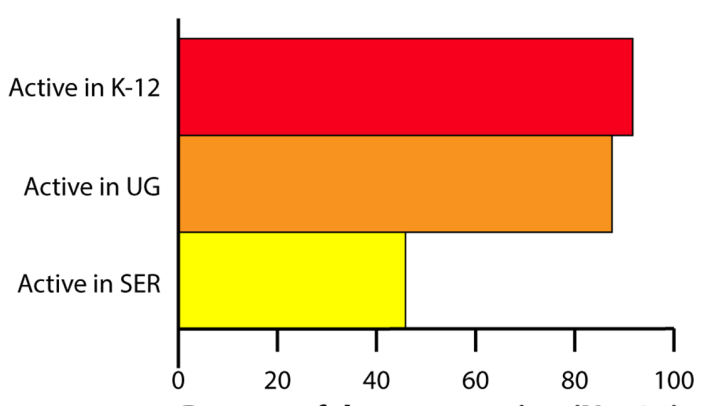

Percent of deans reporting $(\mathbf{N}=\mathbf{2 4})$

\section{B. Perceptions of SFES growth}

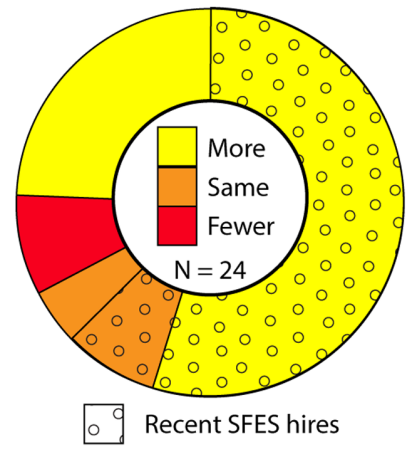

FIGURE 2. Deans' perceived impacts and growth of SFES. (A) Perceived SFES impacts in: $K-12$ science education (K-12; 22 of 24), undergraduate science education (UG; 21 of 24), and science education research (SER; 11 of 24). (B) Deans' perceptions of how the number of SFES in their college has changed in the last 10 years (19 of 24 reported more SFES, three of 24 reported approximately the same number of SFES, and two of 24 reported fewer SFES) overlapped by deans who reported recent SFES hires (15 of 24; dots).

science education. But they're going to have rigorous expectations. It can't be watered down. They have to have the respect of the 'scientists' in the college. I wouldn't mind that at all. I think it's incredibly valuable." -Dean 120

\section{Research Question 3: What Are Deans'} Perceptions of SFES Impacts?

Deans across the CSU system reported impacts of SFES on their campuses in all three arenas of science education: $\mathrm{K}-12$ science education, undergraduate science education, and science education research. Additionally, deans often acknowledged indirect impacts SFES had on their campuses, in terms of being pedagogical and research resources for colleagues and as leaders and change agents in diverse campus initiatives. We share here quantifica-

\begin{abstract}
"[Historically] education was, I don't want to [say] second tier-But it was what you did if you couldn't ... [Now] I think it's changing. They've [departmental faculty] changed. That they were willing to take a precious faculty line and spend it on [education] made it clear that they finally realized that this was a discipline that they needed to address just like cell biology or anything else ... I think [this] means that there's a sort of sea change."-Dean 131
\end{abstract}

\section{Status Differentials between Education and Science}

As seen in the last quote in the previous section, many deans explicitly acknowledged or implicitly evidenced deficit stances toward education as a discipline, which appeared to influence their conceptualizations of SFES and their professional efforts:

\footnotetext{
"You know, I'm a scientist, and I've done a lot with education over the years. But I don't want to-for whatever reason-be identified as that. I think there's a bit of a stigma there that the education people aren't as serious about the science. Or they're more interested in the pedagogy than they are the science. And I think scientists, in general, are more interested in the science."-Dean 116
}

"And so, from a dean's point of view and even a department's point of view, do they want to 'sacrifice'-and that's the way they look at it-a faculty position for education? It's just not the priority of the department. And I understand that. On the other hand, these days we certainly need students who have some comprehension of science. And we need people to be able to teach. And we have to train the teachers. So, from a societal point of view, of course, it's essential. And you want people, I think, with degrees in those subject areas to do that training, provided they're also trained in pedagogy." -Dean 146

“... I do think it's an incredibly important area. I mean, we as scientists need all the help we can get to educate students, to figure out the best ways to use all the technology and so on. Actually, you know, I would welcome having a department of tion of the types of SFES impacts reported during interviews with deans, as well as qualitative evidence about SFES impacts beyond the three arenas of science education.

In querying deans about their perceptions of the impact of SFES on their campuses, all deans reported SFES impacts in at least one arena of science education (Figure 2A). Ninety-two percent (22 of 24) of deans perceived SFES impacts in K-12 science education, including efforts in pre-service teacher preparation, in-service teaching professional development, and partnerships with local schools. Additionally, a similar proportion of deans (88\%; 21 of 24) acknowledged SFES impacts in the arena of undergraduate science education, including faculty professional development, innovations in teaching, and curricular reform and revision. Less than half of deans discussed SFES impacts in terms of science education research (46\%; 11 of 24).

In addition to extensive reports of SFES contributions in the three arenas of science education, deans also reported SFES impacts as resources for their peers in promoting student success, informing teaching and curricular revision, and even in supporting peers in embarking on education research efforts, as shown in the following statements.

"I think they're [SFES] seen as resources that we can tap into that will help us be more successful, particularly in the context of current CSU ideas and plans that probably shouldn't be seen as so novel, student success probably should have been important from the beginning."-Dean 109

"I think having an education-based research person or discipline-based education person in the department enables a two-way conversation that as curriculum is created or adapted, there's a good exchange of ideas and faculty can incorporate those into whatever they're doing in the classroom." -Dean 129

"... there are a number of faculty throughout all of the departments in the college who have an interest in science education research and are utilizing it to answer certain questions, but they don't know how. I've seen them come to these new 
[DBER-focused SFES] and sit down and discuss things with them. There've been a couple of research projects come out in the last year as a result of those discussions."-Dean 100

Some deans saw SFES impacts on their campuses as going far beyond individual efforts and moving toward SFES being leaders, change agents, and culture changers.

"[There] is the expectation that these faculty will be sort of thought leaders when it comes to pedagogy. And when I say pedagogy, I mean as it's practiced on campus ... They expect these people to be involved in faculty professional development, and in fact, they have been involved and very active in helping spread the word about best practices within the departments in the college."-Dean 139

\section{Research Question 4: What Are Deans' Perceptions about the Motivations for Inclusion of SFES in Science Departments?}

Deans were particularly interested in including SFES in their colleges to obtain grant funding earmarked for science education and to address policy mandates linked to increasing retention and graduation rates and fostering $\mathrm{K}-12$ connections. Even though deans recognized the many potential impacts that SFES can make in these areas, they highlighted the pivotal role that departmental faculty played in initiating the hiring of SFES. Overall, most deans reported that they played a substantive role in hiring SFES (15 of 24), a minority expressed they did not play a substantive role (two of 24) or did not clearly articulate their potential role (two of 24), or shared no information on this topic because there had not been a recent SFES hire (five of 24).

\section{Money as a Motivator for SFES Inclusion}

When probed about their perceptions of what motivated SFES hiring by science departments on their campus, the most prevalent reason offered by CSU deans was the ability of SFES to bring grant monies to their campus, as evidenced in a subset of interview quotes:

"And one of the real, key things that immediately sways a chair is if somebody gets grant money. And right now this is an area where people who are doing this [SFES] stuff have real solid access to grant money ... So that convinces chairs very quickly."-Dean 135

"... we need for a certain percentage of our faculty to have grants. And one of the things I thought was that science education faculty will have a higher probability of doing well in grants than others. So, it was a good thing to do from that perspective."-Dean 106

"[Our current SFES] brings in an enormous amount of grant money and has very close ties with the $\mathrm{K}-12$ community in the region. We don't want to lose that. So, the impetus for doing this [replacement] hire is really to bring someone on board to continue what they are doing and go after some of the grant money in the $\mathrm{K}-12$ science education area and help out the local K-12 folks as much as possible."-Dean 100

“... And I guess if you want to be completely utilitarian about this, you could say that once NSF and NIH started focusing on science plus education, then when funds become available, most people follow the money."-Dean 122

Policy Mandates as an Additional Driver for SFES Inclusion In addition to extensive evidence that the combination of available grant monies in science education and the likelihood of SFES bringing resources to campus was a key driver in SFES hiring, deans also referenced a variety of institutional, regional, and statewide policies as influential in decisions about hiring SFES into science departments.

"[SFES hiring is] also driven by an increased emphasis on graduation rates coming from the state. We are receiving pressure. Future funding may be tied to retention and graduation rates, which is a spur for people to consider, "What can we do to improve the situation for our students?"'-Dean 106

“... we're all working under Graduation Initiative 2025. To reach those graduation rates ... work[ing] diligently with changing the lower-division classes, trying to remove all the bottleneck classes ... So, we're all talking about high-impact practices. We're also talking about improving retention, improving graduation rates."-Dean 116

"I think ever since I've been here there's been a very strong push to work with K-12, you know, because [our institution] does serve [a large metropolitan school district]. And, science education has always been an issue. And, my college has always had some faculty with close ties with the College of Education. So, the idea of Science Faculty with Science Education Specialties has always been talked about on this campus."-Dean 120

\section{Central Role of Departments in SFES Inclusion}

Given that key drivers of SFES hiring appear to be opportunities to secure grant money and responding to education policy mandates, one might predict that campus administrators would be the individuals promoting SFES hiring in science departments. While there was variability across campuses, science department faculty themselves were often credited by deans as driving requests for SFES hiring within their own departments, often after much conversation and resolution of skepticism about these types of faculty positions.

\footnotetext{
"... for some departments, there was real reluctance and resistance to hiring [SFES] in those departments, and so it was working with the department chairs to try to overcome that. But if it is the case that a department is viewed as hostile to this sort of hiring when the candidate comes in and interviews, the likelihood of getting a good candidate is pretty small ... Some departments viewed themselves as being primarily focused on producing research grants and viewed that as a major role and were worried that this [SFES] person wouldn't produce the same sort of grants that would involve students. And so they were a little more hesitant."-Dean 126
}

"Since I've been here, it's been the faculty ... just speaking for the hiring that's happened in the 10 years I was there, it's faculty-driven. They determine what they're looking for, what qualifications they want. And then they determine how those 
qualifications can be met. I was working with them pretty closely and helping them strategize successful approaches to casting a broad net, to making sure that we're including the qualifications that will actually make this person successful and that sort of thing. So I basically supported their goals, what they were trying to do, and gave them advice on how to send the ad to attract the best candidate."-Dean 139

\section{Research Question 5: How Do Deans Perceive the Evolution of the SFES Phenomenon over the Last Decade?} We asked deans about their perceptions of how the SFES phenomenon has or has not changed over the last decade. While not all deans had been in their administrative positions for a decade, some (eight of 24) had, and most offered their perspectives, having been on their campuses in some position over that period of time. We share here the quantification of how many of the CSU campuses have experienced increases in SFES, as well as insights from the deans about issues related to the long-term success of the SFES phenomenon.

When probed about changes in the number of SFES on their campus over the last decade, the majority of deans reported increased or similar numbers of SFES on their campus (Figure 2B). Nearly $80 \%$ of deans (19 of 24) reported increased numbers of SFES on their campus now compared with 10 years ago, whereas three deans reported similar numbers, and two deans reported decreased numbers of SFES. Additionally, 63\% of deans (15 of 24) shared that there had been recent hiring of SFES in science departments on their campus (Figure 2B). Perhaps surprisingly, a quarter of the campuses where deans reported growth in the number of SFES, the number grew without recent hires (six of 24). This may indicate a growth in the number of T-SFES at these institutions. Multiple deans referenced that budget cuts across the CSU had been a key influence on the SFES phenomenon and that the increase or maintenance of SFES positions in the presence of budget cuts was evidence of their importance.

\begin{abstract}
"I think we would really like to see more hiring in this area across the college. We'd like to see, for example, somebody in each department with this kind of expertise. The real difficulty is that because of all the budget cuts, at least our university responded by reducing hiring for a long period of time ... I think [SFES numbers have] pretty much stayed the same, but that means we've emphasized something ... recognizing the value of something and being in a situation where you can effectively implement it the way it would ideally be implemented are not always possible."-Dean 135
\end{abstract}

In reflecting on the evolution of the SFES phenomenon over time, several deans mentioned the importance of critical mass of SFES on a campus, as reflected in the following statements:

"I firmly believe that you can't just hire people as islands. You need to have a critical mass of people to be effective, and so when that interest has risen up, we will often have a conversation about the strategic hiring before we put in our budget requests. And we talk about the possibility of maybe in a specific year hiring two or three people, so that we do have a critical mass."-Dean 129

\begin{abstract}
"We're hoping that we're kind of forming a nucleus and these people will work together so we can get some synergy going there ... I think [SFES are] incredibly valuable. Now, whether we can kind of capitalize on the handful that we have now in the college, and if they can work together and we start seeing grants, I wouldn't mind throwing in more positions into the various departments."-Dean 120
\end{abstract}

\section{DISCUSSION}

Previous research has extensively investigated SFES themselves - the nature of their positions, their training, perceived impacts in their departments, and much more; yet the perspectives of stakeholders such as dean-level administrators about the SFES phenomenon have not been explored (Bush et al., $2008,2013,2016,2019)$. While some of the findings from the current study of deans' perceptions of the SFES phenomenon may be expected, the field of higher education needs to move from casual assertions to evidence-based descriptions of the change landscape, grounded in data. Given calls for evidence to drive changes in teaching and learning in higher education, it would seem a logical extension that evidence should also inform and drive change processes in colleges and universities. To address this gap in the STEM education reform research literature, we have collected systematic evidence from deans in the largest university system in the United States. These particular administrators were targeted for study, because these individuals are in positions in which they exert power over the approval of faculty searches and hires and the retention, tenure, and promotion processes for faculty across multiple STEM departments and units. Moreover, these administrators set an institutional tone-whether formally or informally-about the roles of research and teaching at their institutions, the relations between education and science, and the relative importance of pedagogical reform in STEM in higher education. In the following sections we explore three key findings that emerged from analyses of these interview data. First, we address the "elephant in the room," the perception that SFES are working to change a culture of science that is biased against education, a bias freely shared by many of the deans in our study. Next, we examine deans' perceptions that, despite cultural challenges, the SFES phenomenon has persisted over the last decade and continues to grow. Third, we explore how deans perceive the influences of funding opportunities, policy mandates, and departmental desires for change agents and how they impact decisions regarding SFES. In addition, we identify fundamental limitations of the study.

\section{Can SFES Thrive and Actualize Change in a Culture of Science That Is Biased against Education?}

Bias against education within the sciences is considered by many to be commonplace, and evidence collected in the current study demonstrates that this bias is present even among science administrators. Evidence from some deans in the current study suggested the deans' desires not to be associated with or labeled as educators, with the implication that such an association would result in lower status. In addition, there was an undercurrent of language that suggested that DBER would not be considered "real" research or "science" research, but rather something "other" and outside the science disciplines. 
While these ideas are perhaps not surprising to many, it is striking that these messages were communicated by dean-level administrators in interviews with researchers conducting this very type of research. This suggests that the bias is so explicit and commonplace that there is little to no caution in expressing it. In fact, SFES positions in some institutions outside the CSU are more explicitly structured to reflect this bias against the scholarly value of education. In some cases, previous research has shown SFES are hired into non-tenure track positions, disenfranchised in the academic culture as compared with tenure-track and tenured colleagues, and tasked with attending to educational issues so that the "real" scientists do not have to concern themselves with those issues (Bush et al., 2013, 2017, 2019; Harlow et al., 2020). As an additional contrast to the CSU, SFES at other institutions may be in tenure-track positions that are parallel to others in their department but named differently than other disciplinary colleagues, the most notable example being the Lecturer with Potential for Security of Employment track in the University of California system (University of California Office of the President, 2018). Recent research on these particular positions supports the notion that these structures represent disciplinary bias against education efforts in the sciences (Harlow et al., 2020), setting up a separate system for those whose scholarly work is focused on disciplinary education practice and research. Such "disciplinary hegemony" - in the words of one dean in our study-may be key to the success or failure of not only SFES themselves, but evidence-based STEM education reform efforts in higher education more generally.

More theoretically, historical evidence shows how scientists have engaged in boundary work in an effort to distinguish science from non-science and to construct a social and intellectual boundary that ascribes certain characteristics to science (Gieryn, 1983, 1995, 1999). While boundary work has its origins in the demarcation between science and religion, SFES may represent a new realm of boundary work that distinguishes a distinctly science discipline-based approach to science education-with unique approaches, values, and cultural normsfrom a traditional social science approach to science education (Lamont, 2001; NRC, 2012). The extent to which the SFES phenomenon reflects an explicit attempt by scientific disciplines to engage in boundary work in science education is unclear; perhaps the common requirement that SFES are "card-carrying scientists" emerges more from implicit biases about professional identity within the culture of science than explicit boundary demarcations (Brownell and Tanner, 2012; Wooten, 2018, 2019). As shown in previous research on SFES (Bush et al., 2008 , 2013), the absence of joint appointments or more extensive collaborations with colleges of education, alongside a preference for basic science credentials over science education training in the desired professional qualifications of SFES, suggests that SFES positions represent the construction of a clear boundary between these discipline-based science education efforts and traditional science education efforts in colleges of education.

The implicit and explicit bias against education and education research would seem to be an impediment to STEM education reform efforts. Bias against education within the sciences would seem to be no different from other forms of discrimination, except in its current acceptance in higher edu- cation. SFES are now being hired into science departments because of the resources and expertise that they might bring, as well as the institutional mandates that they may address. Integration and inclusion of science education and SFES into the fabric of the science disciplines have the potential to fundamentally broaden and enrich these disciplines, bringing diverse perspectives and interdisciplinary expertise that has been shown in organizational psychology to generate solutions to complex problems (Rock and Grant, 2016). However, in many cases, SFES may be tolerated rather than included and not necessarily integrated as coequal scholars in their disciplinary departments. If tolerance of SFES does not shift toward inclusion of SFES, one wonders whether the SFES phenomenon will wane if the funding sources and policy mandates to improve STEM higher education recede. This could be investigated in future studies.

\section{How Has the SFES Phenomenon Persisted and Expanded in the Face of Cultural Challenges?}

Strikingly, every dean interviewed in this study could identify and discuss the professional efforts of current or former SFES on their campuses. The majority of deans reported that the numbers of SFES on their campuses have increased over the last decade and that recent SFES hiring has occurred. This is noteworthy, given the disciplinary tensions that SFES face within science departments (as found in this study and as noted in other situations; Brownell and Tanner, 2012) and the budget constraints that have been pervasive in recent years (Newell, 2009; Oliff et al., 2013). The increase in the number of SFES in the CSU over the last decade indicates that the benefits of the SFES phenomenon outweigh the challenges associated with these types of positions. The growth of the phenomenon in the face of budget cuts could indicate that the hiring of SFES has been prioritized over other types of faculty hires, at least at some campuses. Multiple deans aspired to foster a critical mass of SFES in their college, aiming for "one in each department." SFES themselves have also called for multiple SFES hires across a college to reduce the isolation felt by some SFES and to promote collaborations and longterm success (Bush et al., 2008). One might ask at what point having an education specialist in a science department will be as expected as having a geneticist or an ecologist in a biology department or an organic or inorganic chemist in a chemistry department.

Most deans in our study reported that they played an important role in ushering SFES into science departments. In higher education generally, deans often play essential roles in initiating departmental change (Jones and Rudd, 2008) and science education reform efforts (May et al., 2013). Additionally, a previous nationwide survey of SFES in the United States has revealed that responding to administrator desires related to education was perceived as a common reason for hiring an SFES (Bush et al., 2017). However, deans participating in this study highlighted that the departmental ecosystem has to be ready for hiring an SFES and that department faculty must be a main driver of the hire. In this light, some deans recommended that SFES would be well served to focus their initial professional efforts on undergraduate science education-as opposed to $\mathrm{K}-12$ science education-to appease departmental colleagues who may have a "what's in it for me" lens about including SFES in their departments. Such differences in perceptions 
may lead to the lack of clarity and agreement about the purpose of SFES positions among deans, departments, and SFES themselves, suggesting that more cross-unit communication about the goals and evaluation of these positions is warranted (Bush et al., 2006, 2011, 2015).

Findings from deans about who is eligible to be an SFES raise questions about how departmental leaders and nonSFES science faculty conceptualize "appropriate" credentials for an individual hired as an SFES. To what extent do departments have explicit conversations about whether they would hire an individual with a $\mathrm{PhD}$ in education? To what extent are assumptions about "appropriate credentials" implicit in the cultural norms of the science disciplines? And how might these implicit assumptions be related to other forms of implicit bias that arise in hiring someone who is a "good fit" for a science department? Future studies of the departmental processes that resulted in SFES hiring-perhaps interviews with department chairs and/or surveys of non-SFES departmental faculty-could reveal the historical processes and decisions made about how educational expertise has been integrated or not into science departments.

\section{What Influences the Decision Makers?}

Deans consistently communicated that the ability of SFES to bring in grant monies focused on science education, particularly in response to federal and state mandates, was an important rationale driving their inclusion in science departments. This strongly suggests that the growth of SFES numbers (Bush et al., 2019) may be closely tied to STEM education funding and policies at both the federal and state levels. For decades, national funding agencies have invested in STEM education both directly through science education grant programs (NSF, 2009, 2010, 2012, 2019b; Howard Hughes Medical Institute, 2019) and indirectly through the broader impacts component of all NSF research proposals beginning in 1997 (NSF, 2015; Duke Science and Society, 2019). In parallel, a variety of STEM education reform policies at the national and state levels (AAAS, 2011; PCAST, 2012; NGSS, 2013; California Science Project, 2014; CSU, 2019a,b)—targeting both K-12 and postsecondary institutions-have provided guidance, support, and mandates for change efforts in science education. Because budgets and external funding are central to a dean's role in managing a college (Martin, 1993), it is perhaps not surprising that national and state grant mechanisms and policy mandates in STEM education have influenced deans' perspectives on SFES. In fact, recent research demonstrated increases in SFES garnering funding for their campuses over the last decade (Bush et al., 2008, 2013, 2019). This is in spite of the disconnect between success in obtaining science education funding and the formal science education training of an SFES, which has previously been reported (Bush et al., 2013). One might reasonably ask, to what extent is the emergence of SFES an unintentional consequence of external reform strategies? If indeed it is unintended, given strong evidence of SFES positive impact as change agents and strong evidence of a pervasive cultural bias against science education (even from among advocates), how could SFES become a more intentional reform strategy? Further, how sustainable is the SFES approach and its impact on reform efforts if the external drivers influencing decision makers go away?
Beyond responding to funding pressures and external mandates, deans reflected that SFES were attractive to some science departments because they served as pedagogical and educational research resources for their peers, often functioning as change agents who lead reform initiatives. This highlights the perceived added value of investing in SFES within departments and colleges, as these individuals contribute beyond their own classroom teaching and research programs, particularly in the arenas of $\mathrm{K}-12$ and undergraduate science education. These deans' perspectives offer triangulation that validates existing self-report data from SFES that they serve as local change agents and influence the teaching practices of their departmental colleagues (Bush et al., 2016, 2019). Additionally, these findings align well with the notion that deans' decisions, in this case supporting the hiring of SFES, play a critical role in the development and implementation of science education reform efforts (May et al., 2013). Given that SFES seem poised to act as change agents within their departments and colleges (Bush et al., 2008, 2013, 2016), one wonders what barriers might limit realizing this potential, including perhaps the structure of the SFES position itself and its tenure/non-tenure status, as well as disciplinary tensions between science and education approaches more generally (Brownell and Tanner, 2012).

While many deans articulated the importance of research and publication as key scholarly activities that earned SFES credibility within their science departments, intriguingly, these were not what deans identified as the most important impacts of SFES. Rather, deans point to local efforts in curricular reform, pedagogical professional development with fellow faculty, direct teaching, and service to promote student success as important SFES impacts. Further, research and publication was not reported by deans as a motivation for SFES hiring. As such, research and publication appear to be a tacit requirement for SFES success and integration into the culture of science, even though it is not considered to be the core expected work or added value of the presence of SFES in a department. Additionally, even when SFES were conducting research and publishing in science education, these scholarly accomplishments were often discussed as not being relevant to the core science discipline. Rather, the language used by several deans suggested that science education research was "other" research and "not real science," evidencing that some deans hold deficit mindsets toward education research, even peer-reviewed, DBER publications.

While the challenges of integrating interdisciplinary scholars into existing disciplines are neither unknown or unexpected, these tensions seemed to strongly influence deans' perspectives and language about SFES in this study. These findings reflect the tension between the motivations for SFES hiring by departments and how SFES gain-or do not gain-professional status and advancement in their departments. This disconnect suggests that SFES are perhaps unfairly expected to accomplish more than non-SFES faculty peers in similar academic positions. SFES are expected to accomplish science education reform and innovation, which may or may not also drive research and publication, and still publish. Depending on the background of the individual SFES, they may not have the scholarly training in education to accomplish such research and publication. Indeed, formal training in education would appear to disadvantage an SFES candidate in the hiring process on 
many campuses, yet would be essential to producing scholarly research publications seen as critical to success in a science department.

Disconnects between SFES hiring motivations and subsequent disciplinary tensions reported by deans are consistent with previous findings from SFES about misalignments between stated reasons for their hiring and their perceived criteria for their subsequent evaluation and retention (Bush et al., 2006, 2015, 2017). Additionally, recent research has shown that SFES themselves distinguish their role as education specialists, fostering science education reform, from the added role that some also have as discipline-based education researchers (Bush et al., 2019). The lack of alignment between the perceived added value of SFES and the tacit expectation to also conduct research and publish harkens back to the perennial question about how higher education might differentiate and value multiple types of faculty work (Boyer et al., 2015). While seemingly unrelated, the SFES situation brings to mind the invisible burdens on women and scientists of color within science departments. Research increasingly documents that such individuals are expected to contribute extensively toward work that is invisible or not valued in the tenure and promotion process, while also being expected to be as productive in their scholarship as their departmental peers who do not have these additional expectations (NSF, 2019a).

\section{Limitations and Considerations}

While this study represents a systematic investigation of deans' perceptions of the SFES phenomenon, there are important limitations to be considered in interpreting these data. First, we elected to request only a 30-minute interview with each dean, anticipating that a lower time request would incentivize more participation. The evidence presented here does indeed represent perspectives from all but one CSU campus; however, more detail undoubtedly could be learned from additional and longer interviews. Given the nature of these time-limited interviews, we were unable to systematically probe all themes that emerged with each individual. As such, post hoc quantification of the proportion of deans who endorsed each particular idea was not possible. In this light, we took great care in the language of the Results to not generalize ideas to all dean participants. Finally, the evidence collected here reflects the perceptions of only CSU deans. As the largest university system in the United States, the CSU does include institutions ranging from teaching-focused PUIs to highly research-active and PhD-granting institutions that reflect much of the variation in institutions of higher education across the nation. Like prior results, in which we found that SFES at a variety of institutions across the United States share common characteristics previously observed in CSU SFES (Bush et al., 2013), we expect to see the perceptions of deans shared among campuses within and outside California. However, the extent to which similar findings would be found among deans and chairs at other institutions remains to be seen.

\section{CONCLUSIONS AND FUTURE DIRECTIONS}

While the SFES phenomenon has been well described and appears to have persisted and expanded over the last decade, the perspectives of academic leaders such as college deanswho have power and influence over the academic culture of science and the hiring of science faculty-have not been systematically studied. Here we have reported the perceptions of science deans from the largest university system in the United States on the SFES phenomenon, including their awareness of SFES and their impacts, their conceptualization of these positions, their impressions of motivations for SFES hiring, and the evolution of the SFES phenomenon over the last decade. Even though deans were aware of SFES and were positive about the ability of SFES to improve science education, most deans also mentioned bias against science education in general and SFES in particular. Deans shared that SFES with $\mathrm{PhDs}$ in science (rather than education) were more likely to be accepted by their colleagues and that publishing their research was crucial for SFES success. Additionally, deans reported that the growth of the SFES phenomenon over the last decade has been fueled by external funding and external policies that call for science education reform, so what might happen to the SFES phenomenon when external forces change? Currently, our findings reveal that science education and SFES are sometimes being tolerated by scientists in higher education rather than being equitably included as part of the fabric of biology, chemistry, geoscience, and physics departments.

The findings here suggest multiple lines of future research that would expand our understanding of the SFES phenomenon. In particular, our results point to the pressing need for additional systematic investigations of the complex status relations between the fields of science and education, which has ramifications far beyond the SFES phenomenon. Additionally, the emergent concerns here could drive the development of a survey instrument to enable the study of deans' perspectives on these issues across a large number of institutions both nationally and internationally.

\section{ACKNOWLEDGMENTS}

We thank the CSU Colleges of Science deans who took time to share their perspectives on the SFES phenomenon in their colleges through interviews with us and to review initial drafts of this report. Additionally, we thank the two anonymous reviewers and the LSE monitoring editor for their constructive input on this article. We thank N. Pelaez and J. Rudd for their involvement in earlier research on SFES that set the stage for the current work, as well as our families for their ongoing patience and support. This study was supported by the Helmsley Trust and STEM Collaboratives grant 2014PG-EDU036 administered by the CSU Chancellor's Office.

\section{REFERENCES}

Addy, T. M., Simmons, P., Gardner, G. E., \& Albert, J. (2015). A new "class" of undergraduate professors: Examining teaching beliefs and practices of science faculty with education specialties. Journal of College Science Teaching, 44(3), 91-99.

American Association for the Advancement of Science. (2011). Vision and change in undergraduate biology education: A call to action Washington, DC

Association of American Universities. (2017, October 3) Lecturers with the Potential for Security of Employment. Retrieved October 28, 2019, from www.aau.edu/lecturers-potential-security-employment

Boyer, E. L., Moser, D., Ream, T. C., \& Braxton, J. M. (2015). Scholarship reconsidered: Priorities of the professoriate. San Francisco, CA: Jossey-Bass.

Brainard, J. (2007). 50 years after Sputnik, America sees itself in another science race. Chronicle of Higher Education, 54(7), A22-A23. 
Brownell, S. E., \& Tanner, K. D. (2012). Barriers to faculty pedagogical change: Lack of training, time, incentives, and ... tensions with professional identity? CBE-Life Sciences Education, 11(4), 339-346.

Bush, S. D., Pelaez, N. J., Rudd, J. A., Stevens, M. T., Tanner, K. D., \& Williams, K. S. (2008). Science faculty with education specialties. Science, 322(5909), 1795-1796.

Bush, S. D., Pelaez, N. J., Rudd, J. A., Stevens, M. T., Tanner, K. D., \& Williams K. S. (2013). Widespread distribution and unexpected variation among science faculty with education specialties (SFES) across the United States. Proceedings of the National Academy of Sciences USA, 110(18) $7170-7175$.

Bush, S. D., Pelaez, N. J., Rudd, J. A., Stevens, M. T., Tanner, K. D., \& Williams, K. S. (2015). Misalignments: Challenges in cultivating science faculty with education specialties in your department. BioScience, 65(1), 81-89.

Bush, S. D., Pelaez, N. J., Rudd, J. A., Stevens, M. T., Tanner, K. D., \& Williams, K. S. (2011). Investigation of science faculty with education specialties within the largest university system in the United States. CBE-Life Sciences Education, 10(1), 25-42

Bush, S. D., Pelaez, N. J., Rudd, J. A., Stevens, M. T., Tanner, K. D., Williams, K. S., \& Wood, W. B. (2010). A role for postdocs in undergraduate education. Science, 327(5965), 522-523.

Bush, S. D., Pelaez, N. J., Rudd, J. A., Stevens, M. T., Williams, K. S., Allen, D. E., \& Tanner, K. D. (2006). On hiring science faculty with education specialties for your science (not education) department. CBE-Life Sciences Education, 5(4), 297-305.

Bush, S. D., Rudd, J. A., II, Stevens, M. T., Tanner, K. D., \& Williams, K. S. (2016). Fostering change from within: Influencing teaching practices of departmental colleagues by science faculty with education specialties. PLoS ONE, 11(3), e0150914

Bush, S. D., Stevens, M. T., Tanner, K. D., \& Williams, K. S. (2017). Origins of science faculty with education specialties: Hiring motivations and prior connections explain institutional differences in the SFES phenomenon. BioScience, 67(5), 452-463

Bush, S. D., Stevens, M. T., Tanner, K. D., \& Williams, K. S. (2019). Evolving roles of scientists as change agents in science education over a decade: SFES roles beyond discipline-based education research. Science Advances, 5(6), eaav6403.

Bystydzienski, J., Thomas, N., Howe, S., \& Desai, A. (2017). The leadership role of college deans and department chairs in academic culture change. Studies in Higher Education, 42(12), 2301-2315.

California Science Project. (2014). Regents of the University of California, California Subject Matter Project. Retrieved October 28, 2019, from https://csmp.ucop.edu/csp

California State University (CSU). (2019a). Graduation Initiative 2025 Retrieved October 28, 2019, from www2.calstate.edu/CSU-system/ why-the-CSU-matters/graduation-initiative-2025/Pages/default.aspx

CSU. (2019b). Mathematics and Science Teacher Initiative (MSTI). Retrieved October 28, 2019, from www2.calstate.edu/impact-of-the-CSU/teacher -education/Pages/math-science-teacher-initiative.aspx

CSU. (2019c). 2019 Facts about the 23 campuses of the CSU. Retrieved April 21, 2020, from www2.calstate.edu/CSU-SYSTEM/ABOUT-THE-CSU/ FACTS-ABOUT-THE-CSU/DOCUMENTS/FACTS2019.PDF

Chasteen, S. V., \& Code, W. J. (2018). The Science Education Initiative handbook: A practical guide to fostering change in university courses and faculty by embedding discipline-based education specialists within departments. Boulder: University of Colorado Boulder.

Coleman, M. S., Smith, T. L., \& Miller, E. R. (2019). Catalysts for achieving sustained improvement in the quality of undergraduate STEM education. Dædalus, 148(4), 29-46.

Duke Science and Society. (2019). What Are Broader Impacts? Retrieved October 28, 2019, from https://scienceandsociety.duke.edu/research/birc/ what-are-broader-impacts/

Gieryn, T. F. (1983). Boundary-work and the demarcation of science from non-science: Strains and interests in professional ideologies of scientists. American Sociological Review, 48(6), 781-795.

Gieryn, T. F. (1995). Boundaries of science. In Science and the quest for reality (pp. 293-332). London: Palgrave Macmillan.

Gieryn, T. F. (1999). Cultural boundaries of science: Credibility on the line. Chicago: University of Chicago Press.
Harlow, A., Lo, S. M., Saichaie, K., \& Sato, B. K. (2020). Characterizing the University of California's tenure-track teaching position from the faculty and administrator perspectives. PLOS ONE, 15(1), e0227633.

Hénard, F. (2009). Learning our lesson: Review of quality teaching in higher education draft report. Retrieved October 28, 2019, from http://www oecd.org/education/imhe/43961761.pdf

Holm, B., Carter, V. C., \& Woodin, T. (2011). Vision and change in biology undergraduate education: Vision and change from the funding front. Biochemistry and Molecular Biology Education, 39(2), 87-90.

Howard Hughes Medical Institute. (2019). HHMI Inclusive Excellence Initiative. Retrieved October 28, 2019, from www.hhmi.org/science -education/programs/inclusive-excellence

Jones, D., \& Rudd, R. (2008). Transactional, transformational, or laissez-faire leadership: An assessment of college of agriculture academic program leaders' (deans) leadership styles. Journal of Agricultural Education, 49(2), 88-97.

Lamont, M. (2001). Culture and identity. In Handbook of sociological theory (pp. 171-185). Boston, MA: Springer.

Martin, J. L. (1993, April). Academic deans: An analysis of effective academic leadership at research universities. Paper presented at: the Annual Meeting of the American Educational Research Association (Atlanta, GA).

May, D. B., Susskind, D., \& Shapiro, N. S. (2013). Faculty grassroots leadership in science education reform: Considerations for institutional change, culture, and context. Creative Education, 4(07), 22-31.

National Research Council. (2012). Discipline-based education research: Understanding and improving learning in undergraduate science and engineering. Washington, DC: National Academies Press.

National Science Board. (2007). A national action plan for addressing the critical needs of the US science, technology, engineering, and mathematics education system. Washington, DC: National Science Foundation.

National Science Foundation (NSF). (2009). Course, Curriculum, and Laboratory Improvement (CCLI) Program. Retrieved October 28, 2019, from www.nsf.gov/pubs/2009/nsf09529/nsf09529.html

NSF. (2010). Transforming Undergraduate Education in Science, Technology, Engineering and Mathematics (TUES) Program. Retrieved October 28, 2019, from www.nsf.gov/pubs/2010/nsf10544/nsf10544.htm

NSF. (2012). Math and Science Partnership (MSP) Program. Retrieved October 28, 2019, from www.nsf.gov/pubs/2012/nsf12518/nsf12518.htm

NSF. (2015). Perspectives on Broader Impacts (Publication NSF 15-008). Retrieved October 28, 2019, from www.nsf.gov/od/oia/publications/ Broader_Impacts.pdf

NSF. (2019a). ADVANCE: Organizational change for gender equity in STEM academic professions (ADVANCE) program. Washington, DC: NSF ADVANCE. Retrieved October 28, 2019, from www.nsf.gov/funding/ pgm_summ.jsp?pims_id=5383

NSF. (2019b). Improving Undergraduate STEM Education (IUSE) Program. Retrieved October 28, 2019, from www.nsf.gov/pubs/2019/nsf19601/ nsf19601.htm

Newell, M. (2009). Higher education budget cuts: How are they affecting students? (Report 09-27). Sacramento, CA: Postsecondary Education Commission.

Next Generation Science Standards Lead States. (2013). Next generation science standards: For states, by states. Washington, DC: National Academies Press.

Oliff, P., Palacios, V., Johnson, I., \& Leachman, M. (2013). Recent deep state higher education cuts may harm students and the economy for years to come (pp. 1-21). Washington, DC: Center on Budget and Policy Priorities.

Organisation for Economic Co-operation and Development. (2007). PISA 2006: Science Competencies for Tomorrow's World, Vol. 1, Analysis. Paris: OECD Publishing.

President's Council of Advisors on Science and Technology. (2012). Engage to excel: Producing one million additional college graduates with degrees in science, technology, engineering, and mathematics. Washington, DC: U.S. Government Office of Science and Technology. Retrieved October 28, 2019, from http://www.whitehouse.gov/sites/default/files/ microsites/ostp/pcast-engage-to-excel-final2-25-12.pdf

Rock, D., \& Grant, H. (2016). "Why diverse teams are smarter. Harvard Business Review, 4(4), 2-5. 
University of California Office of the President. (2018, October 10) Appointment and Promotion, Lecturer with Security of Employment Series (Apm-285). Retrieved October 28, 2019, from https://ucop.edu/ academic-personnel-programs/_files/apm/apm-285.pdf

Wieman, C. (2009). Galvanizing science departments. Science, 325(5945), 1181

Wieman, C. (2017). Improving how universities teach science. Cambridge, MA: Harvard University Press.
Wooten, M. M. (2018). A cartographic approach toward the study of academics' of science teaching and learning research practices and values. Canadian Journal of Science, Mathematics and Technology Education, 18(3), 210-221.

Wooten, M. M. (2019). A critical materialist entry into the comforts and dangers in defining academics' of science teaching and learning research communities. Cultural Studies of Science Education, 14(1), 231-247.This 